\section{Presas subálveas enterradas en el lecho de ramblas del Sureste de España}

\section{Subalveous dams buried under ramblas riverbeds in southeastern Spain}

\section{José María Gómez-Espín}

Universidad de Murcia

Murcia, España

espin@um.es

(iD) 0000-0001-7287-4952

\section{Información del artículo:}

Recibido: 23 enero 2020

Revisado: 5 mayo 2020

Aceptado: 8 septiembre 2020

\section{ISSN 2340-8472 \\ ISSNe 2340-7743 \\ DOI $\quad 10.17561 /$ AT.18.5234}

\footnotetext{
(c) $\mathrm{CC}-\mathrm{BY}$

(c) Universidad de Jaén (España). Seminario Permanente Agua, Territorio y Medio Ambiente (CSIC)
}

\section{RESUMEN}

En medios áridos y semiáridos como el Sureste de la Península Ibérica, para captar las aguas de subálveos de ramblas, se utilizan sistemas combinados de galería y presa enterrada. Son complejos hidráulicos que obtienen recursos de caudal variable, pero de gran calidad. Solo se pueden obtener aquellos caudales que tras las precipitaciones quedan acumulados en los depósitos de arenas y gravas de los lechos fluviales, recursos que se renuevan tras cada episodio de precipitaciones. En el borde septentrional de la Depresión Prelitoral se mantienen en activo el complejo hidráulico de la rambla de Béjar y los de Los Cotes-Cegarras y Caño-Contracaño en la rambla de Nogalte. Son sistemas locales que aprovechan los freáticos próximos a la superficie para generar recursos propios de agua en medios secos, mereciendo ser conservados como modelos de interés ante escenarios de cambio climático.

PALABRAS CLAVE: Captación de freáticos próximos, Galería drenante, presa subálvea, Sistemas locales de recursos propios de agua, Sureste de España.

\section{ABSTRACT}

In arid and semi-arid environments such as the Southeast of the Iberian Peninsula, water supply systems that combine draining galleries and buried dams are used in order to capture waters in the subsurface of ramblas. They are hydraulic complexes that get variable flow resources, but of high quality. They capture only those water flows accumulated in the deposits of sand and gravel of riverbeds following rainfall, which are renewed each time it rains. On the northern limit of the Prelitoral Depression the one of the Rambla de Béjar and those of Los Cotes-Cegarras and Caño-Contracaño in Rambla de Nogalte remain active. They are local systems that rely on the water table near the surface to generate their own water resources in dry environments, which ought to be preserved as models of interest to be employed in scenarios of climate change.

KEYWORDS: Near water table collection, Draining gallery, Subsurface dam, Local water resource systems, Southeast of Spain 


\section{Barragems enterradas no leito de Ramblas no sudeste da Espanha}

\section{SU MÁRIO}

Em ambientes áridos e semi-áridos como o Sudeste da Península Ibérica, para captar as águas abaixo das ramblas, utilizam-se sistemas combinados de galeria e barragens enterradas. São complexos hidráulicos que obtêm recursos de vazão variável, mais de grande qualidade. Só podem ser obtidos os fluxos que após as chuvas se acumulam nos depósitos de areia e cascalho dos leitos dos rios, recursos que se renovam a cada episódio de chuva. No limite norte da Depressão Pré-litoral, o complexo hidráulico da Rambla de Béjar e os de Los Cotes-Cegarras e Caño-Contracaño na Rambla de Nogalte permanecem ativos. São sistemas locais que aproveitam os lençóis freáticos próximos à superfície para gerar seus próprios recursos hídricos em ambientes secos, merecendo ser conservados como modelos de interesse diante de cenários de mudanças climáticas.

PALAVRAS-CHAVE: Captação de freáticos próximos, Galeria de drenagem, Barragem enterrada, Sistemas locais de recursos hídricos próprios, Sudeste da Espanha.

\section{Barrages enterrés dans le} lit des Ramblas dans le sud-est de l'Espagne

\section{RÉSUMÉ}

Dans les environnements arides et semi-arides tels que le sud-est dela péninsule ibérique, pour capturer les eaux sousla surface des ramblas, des systèmes combinés de galerie et de barrage enterré sont utilisés. Ce sont des complexes hydrauliques qui obtiennent des ressources à débit variable, mais de grande qualité. Seuls ces débits peuvent être obtenus qu'après l'accumulation des pluies dans les dépôts de sable et de gravier des lits fluviaux, ressources qui se renouvellent après chaque épisode de pluie. Sur le bord nord de la Dépression pré-littorale, le complexe hydraulique de la Rambla de Béjar et ceux de Los Cotes-Cegarras et Caño-Contracaño sur la Rambla de Nogalte restent actifs. Ce sont des systèmes locaux qui profitent des nappes phréatiques proches de la surface pour générer leurs propres ressources en eau dans des environnements secs, méritant d'être conservés comme des modèles d'intérêt face aux scénarios de changement climatique.

MOTS CLÉ: Captage des phréatiques proches, Galerie de drainage, Barrage enterré, Systèmes locaux de ressources en eau propres, Sud-est de l'Espagne.

\section{Dighe sepolte nel letto delle Ramblas nel sud- est della Spagna}

\section{SOMMARIO}

In ambienti aridi e semi-aridi come il sud-est della penisola iberica, per catturare le acque sotto la superficie delle ramblas, vengono utilizzati sistemi combinati di galleria e diga sepolta. Sono complessi idraulici che ottengono risorse di portata variabile, ma di grande qualità. Si possono ottenere solo quelle portate che dopo le piogge si accumulano nei depositi di sabbia e ghiaia degli alvei, risorse che si rinnovano dopo ogni episodio di pioggia. Sul margine settentrionale della depressione pre-litorale, rimangono attivi il complesso idraulico della Rambla de Béjar e quelli di Los Cotes-Cegarras e Caño-Contracaño nella Rambla de Nogalte. Sono sistemi locali che sfruttano le falde acquifere in prossimità della superficie per generare le proprie risorse idriche in ambienti asciutti, meritevoli di essere conservati come modelli di interesse di fronte agli scenari di cambiamento climatico.

PAROLE CHIAVE: Captazione delle acque sotterranee vicine, Galleria di drenaggio, Diga interrata, Sistemi locali di risorse idriche proprie, Sud-est della Spagna. 


\section{Introducción ${ }^{1}$}

En medios áridos y semiáridos se ha ordenado el territorio para la captación y uso de las aguas pluviales (con acondicionamientos de laderas, presas de derivación y redes de boqueras, etc.) y también para el alumbramiento y uso de las aguas infiltradas (pozos horizontales y verticales, galerías, sondeos, etc.).

Los geógrafos han prestado atención a estos sistemas de captación y uso de las aguas superficiales y subálveas y a los paisajes que han creado. El Levante español cuenta con buenos ejemplos de ese patrimonio cultural que han sido estudiados por diversos equipos de investigadores ${ }^{2}$. El Sureste Ibérico ${ }^{3}$ (Mapa 1) forma parte de la España seca mediterránea, donde la obtención de recursos propios de agua, a partir de la aplicación de la técnica del pozo horizontal cubierto (galería) asocia- do o inscrito en presa subálvea, tiene gran importancia a nivel local. En su funcionamiento y explotación son modelos de sostenibilidad (ya que solo captan el agua intersticial del álveo, que se recarga tras cada episodio de precipitaciones y no se produce sobreexplotación), por lo que también presenta una gran variabilidad respecto a los caudales alumbrados (siempre acorde a la infiltración de la escorrentía en el espacio anterior a donde se ubica el dren).

El área de estudio es el flanco noroccidental de la Depresión Prelitoral Murciana, comprendida entre los relieves Béticos como la Sierra de Las Estancias y la fosa del Guadalentín-Viznaga. El territorio está drenado por cursos de fluir intermitente como las ramblas de la Torrecilla, Béjar, Nogalte, Vilerda y Góñar (Figura 1). En su perfil longitudinal, entre las cumbres (a más de 1000 metros snm.) y el fondo de la depresión (a menos de 300 metros snm.) se suceden sectores donde disminuye la

Mapa 1. Localización en la región Sureste de los sistemas de galería-presa subálvea

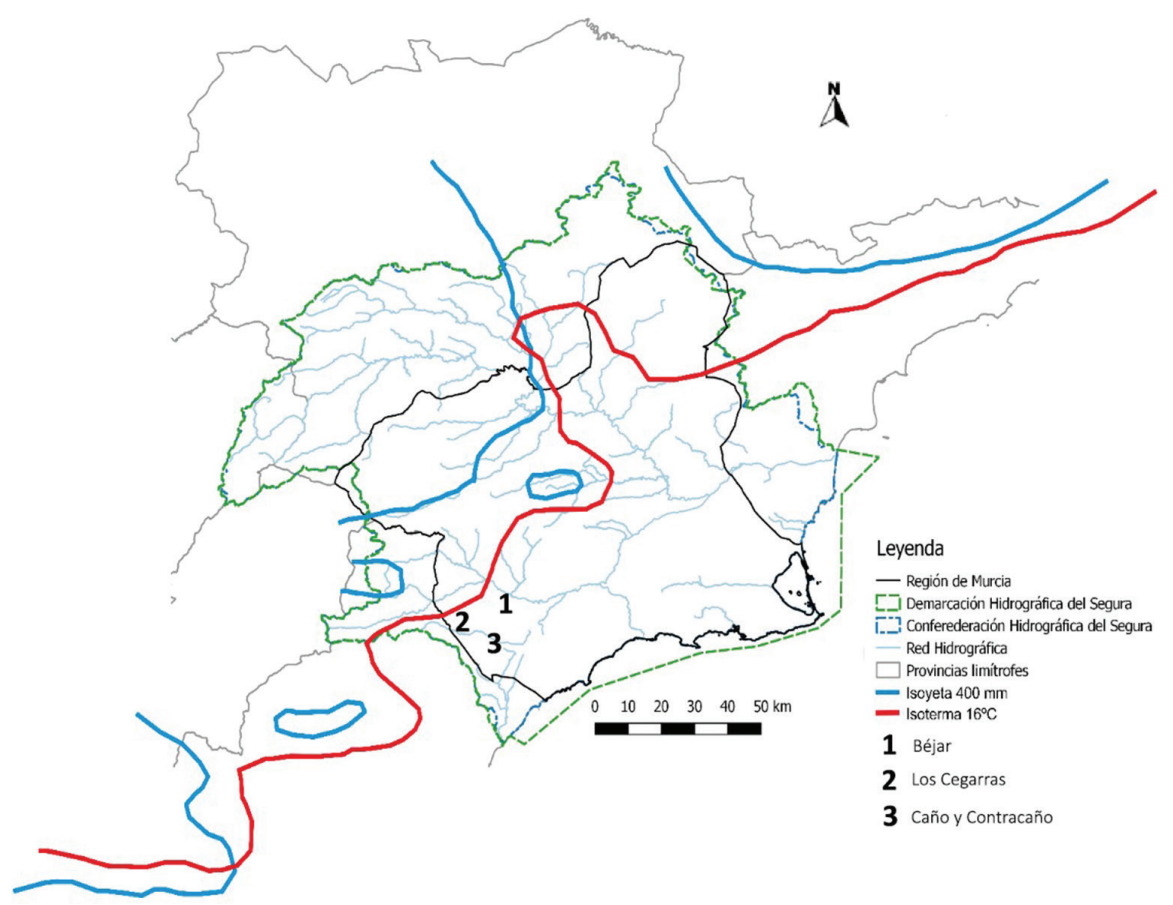

Fuente: Elaboración propia a partir de Gil Meseguer et al., 2014.

1. Esta investigación recoge parte de la información del Proyecto de Investigación SEJ2007-67286GEOG "Modelos de sostenibilidad generadores de recursos propios de agua en el sureste de la Península Ibérica. Los sistemas de galerías con lumbreras y presa subálvea".

2. Para los aprovechamientos de pluviales destacan los trabajos del profesor Alfredo Morales Gil y su equipo de la Universidad de Alicante (Morales Gil, 1968/1969. Morales Gil, Box Amorós y Marco Molina, 1991. Morales Gil y Box Amorós, 1993. Hernández Hernández y Morales Gil, 2013). Para las captaciones de freáticos mediante drenes (sobre todo aguas subsuperficiales y subálveas) el equipo de los profesores Encarnación Gil Meseguer y José María Gómez Espín, de la Universidad de Murcia (Gil Meseguer y Gómez Espín,
1993. Gómez Espín, 2005. Gómez Espín et al., 2007. Aliaga Sola et al., 2007. Gil Meseguer, Martínez Medina y Gómez Espín, 2011. Gil Meseguer, Gómez Espín y Martínez Medina, 2012. Gil Meseguer, García Sánchez y Gómez Espín, 2013. Martínez-Medina, Gil-Meseguer \& Gómez-Espín, 2018) y el Grupo ESTEPA de la Universidad de Valencia dirigido por el profesor Jorge Hermosilla Plá (Hermosilla Plá et al., 2004. Hermosilla Plá, 2006. Hermosilla Plá, 2008. Iranzo García, Antequera Fernández y Hermosilla Plá, 2010).

3. La región Sureste corresponde al territorio delimitado por la línea de costa del Mediterráneo desde el sur del Cabo de la Nao (Alicante) hasta Cabo de Gata (Almería), y hacia el interior por las isolíneas de la isoterma de $+16{ }^{\circ} \mathrm{C}$

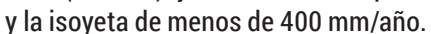


pendiente de forma acusada, formándose depósitos de gravas y arenas que recubren el lecho y donde existe una circulación subsuperficial de agua, incluso varios meses después del fluir en la superficie de la rambla ${ }^{4}$.

La variabilidad de los caudales alumbrados está en función de las precipitaciones y del estado del dren para captarlos. Tras el temporal de los días 15,16 y 17 de diciembre de 2016 (la precipitación acumulada en Tonosa fue de $280 \mathrm{l} / \mathrm{m}^{2}$ y en Puerto Lumbreras de $227 \mathrm{l} /$ $\mathrm{m}^{2}$ ), el caudal captado por el complejo hidráulico CañoContracaño pasó de un aforo de 3 litros por segundo (se tardaba más de cien horas en llenar la balsa) a un aforo de 25 litros por segundo hasta el 20 de marzo de 2017, y de 50 litros por segundo desde el 21 de marzo hasta diciembre de 2017. En el verano de 2019 (meses de junio, julio y agosto), el caudal aforado era de unos seis litros por segundo, tras las precipitaciones ocasionadas por la DANA de los días 12 y 13 de septiembre de 2019 (141,8 $1 / \mathrm{m}^{2}$ en la cabecera de la rambla de Nogalte y $116,0 \mathrm{l} /$ $\mathrm{m}^{2}$ en la rambla a la altura de Puerto Lumberas) se pasó a un aforo de 15 litros por segundo. En enero del 2020, tras la llegada de las aguas infiltradas de las lluvias de la cabecera (Tonosa-Sierra de Las Estancias) aumentó a más de treinta litros por segundo (Figura 2).

En cuanto al origen de la galería drenante (sobre todo del qanat), autores como Goblot se remontan a Armenia y Mesopotamia, y otros como Lighfoot y Magee a la Península Arábiga. A su difusión hacia el este y el oeste contribuirían imperios como los de Roma y Persia, y rutas comerciales como la de la Seda ${ }^{5}$. En cuanto a la técnica del pozo horizontal (dren), Goblot le atribuye un origen minero, mientras que Barceló et al., manifies$\tan$ que no hay una sola arquitectura, cada sistema es un mundo diferente ${ }^{6}$.

En el ámbito del Sureste y en el espacio de la Depresión Prelitoral Murciana, entre los antecedentes de esta investigación hemos de señalar los trabajos de Llobet Reverter y los de Gil Olcina. El primero señalando la venta de aguas captadas del subálveo de la rambla de Nogalte y el segundo el papel de la presa de la Fuente del Oro en el Guadalentín ${ }^{7}$.

Figura 1. Partidor de grandes boqueras en la Ramblilla (Puerto Lumbreras)

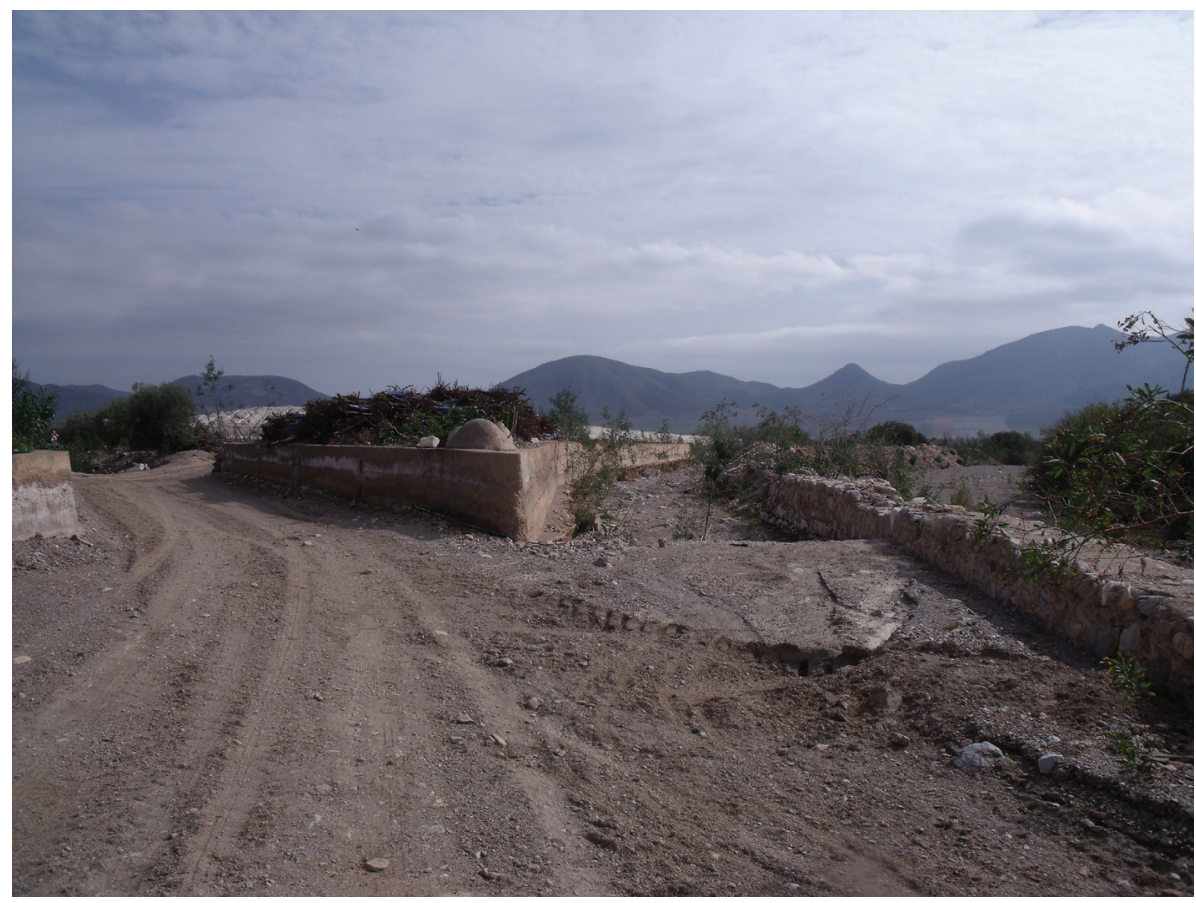

Fotografía de Gómez-Espín, 9 de febrero de 2020.

\footnotetext{
4. Gómez Espín, 2005, 102. Gil Meseguer, 1987, 102. La mayor parte de estos cauces vierten a la red del Guadalentín-Viznaga, pero en situaciones de crecida, de aguas altas, de avenida, atraviesan los umbrales de ambos lados de la Sierra de Enmedio (al norte el umbral del Caballón de la Hoya y al sur el umbral de la Venta Ceferino) y vierten hacia la margen izquierda del Almanzora, dentro de la Demarcación Hidrográfica del Segura. El primero a través de la Rambla de Las Norias-Galían-Pinar y el segundo a través de la Rambla de Charcones-Nogantes-Canalejas.
}

\footnotetext{
5. Goblot, 1979. Lightfoot, 2000. Magee, 2005.

6. Goblot, 1979. Barceló et al., 1986.

7. Llobet Reverter, 1958. Gil Olcina, 1971; 1993.
} 
Figura 2. Antigua balsa que recogía las aguas alumbradas por el sistema de Caño y Contracaño

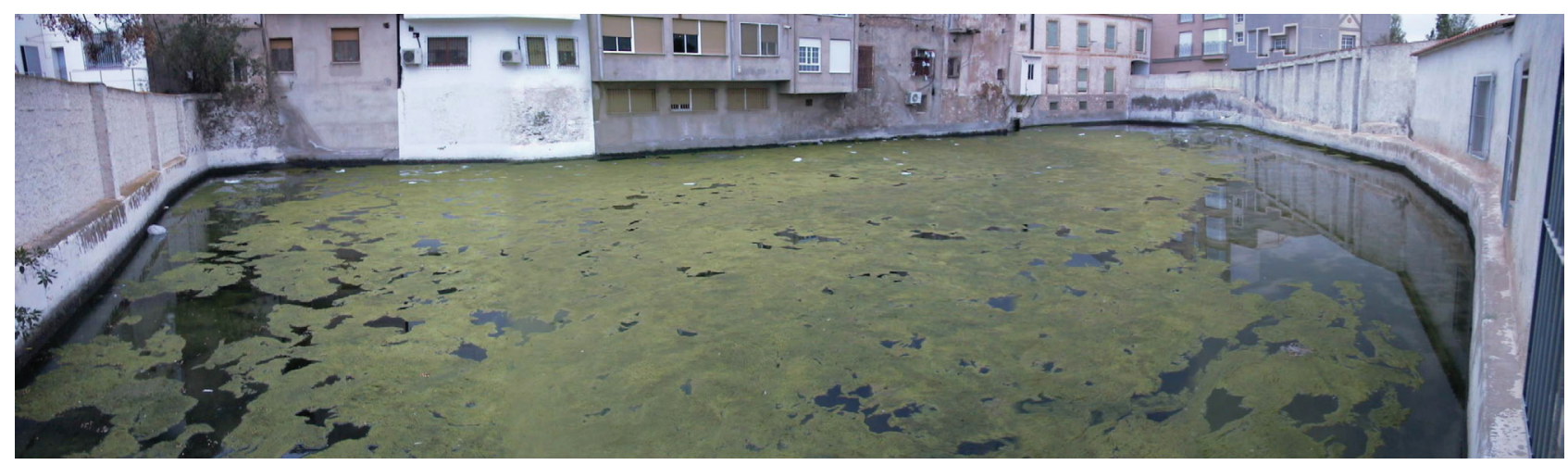

Fotografía de Gómez-Espín, 16 de enero de 2005.

La técnica del pozo horizontal cubierto estaba extendida en un territorio seco como el Sureste donde se disputaban la propiedad y uso de las aguas. En los inicios del siglo XXI existían todavía en activo un gran número de cimbras en el río-rambla Almanzora. En octubre de 2001 la Junta Central de Usuarios de Aguas del Valle del Almanzora (JCUAVA) reflejaba entre los recursos propios la captación de agua por 9 pozos, 2 cimbras y 8 fuentes en el Alto Almanzora; por 12 pozos, 7 cimbras y 8 fuentes en el Medio Almanzora, y por 4 cimbras, 75 pozos y una desaladora en el Bajo Almanzora. Las fuentes eran puntos de emisión de agua captada a través de minados y de qanat. Las cimbras eran una forma de alumbrar agua en los lechos del Almanzora y de su red de afluentes ${ }^{8}$.

\section{Objetivos}

El objeto de estudio de esta investigación ha sido localizar y explicar los principales sistemas de galería drenante que captan subálveos en el lecho de cauces con régimen de fluir intermitente como las ramblas, entre las que destacan: las cimbras o tajeas, las galerías drenantes inscritas o asociadas a presa subálvea, y las conducciones de pozo horizontal cubierto que cuando atraviesan el lecho de una rambla, captan y conducen las aguas freáticas a la superficie y se comportan como galería drenante inscrita en presa subálvea (Tabla 1).

Las cimbras o tajeas son galerías abiertas en los sedimentos de un cauce de fluir intermitente como las ramblas. Por la naturaleza detrítica de los materiales en los que se inscriben, la zanja que se abre necesita que se edifiquen paredes de piedra seca y el techo se cubra con lajas de piedra más grandes y alargadas e incluso se construya una bóveda por aproximación. Las aguas intersticiales se infiltran al interior de la tajea a través de paredes y techo. Al estar construida con cierta pendiente, las aguas se conducen en el interior de la base de la cimbra por gravedad, hasta aflorar a la superficie (bocamina), desde la que se almacena y distribuye.

Las galerías drenantes del tipo qanats se caracterizan por ser un pozo horizontal excavado en un piedemonte, al que en su construcción y para mejor funcionamiento se sitúan pozos verticales (lumbreras, respiraderos, espejuelos, etc.) a tramos más o menos regulares, según la topografía y naturaleza del material en el que se excaven, con objeto de airear la galería y extraer el material de la construcción y el de limpiezas o mondas posteriores.

Las presas subálveas están enterradas en el cauce de ramblas y ríos-rambla para interrumpir la circulación subsuperficial de las aguas entre los depósitos del cauce. Se les antepone o inscribe en la presa una galería drenante, a la que acostumbra a penetrar el agua a través de unos orificios (denominados mechinales, piqueras y troneras) en la pared anterior de la galería, que es la que primero está en contacto y drena el depósito detrítico.

Todas estas aplicaciones de la técnica del pozo horizontal (galería) son soluciones ingeniosas adaptadas a las condiciones de los medios áridos y semiáridos, que generan unos recursos hídricos de caudal variable, pero de calidad (filtradas las aguas en los depósitos de arenas y gravas) y de interés local. En cierto modo la técnica del pozo horizontal cubierto (dren) permite hacer frente a la elevada evaporación que existe en estos medios áridos y semiáridos (evapotranspiración

\footnotetext{
8. Gómez Espín, 2016.
} 
TABLA 1. TIPOLOGÍA DE POZO HORIZONTAL CUBIERTO (GALERÍA)

\begin{tabular}{ll}
\hline Mina de agua & $\begin{array}{l}\text { Galería excavada en la parte alta y media de un relieve. No suelen tener gran longitud de minado. Sin pozos } \\
\text { verticales o con muy pocos respiraderos. }\end{array}$ \\
\hline $\begin{array}{ll}\text { Qanat (galería con lumbreras, viaje de agua, minado } \\
\text { con espejuelos, etc.) }\end{array}$ & $\begin{array}{l}\text { Galería excavada en un piedemonte. Cuenta con "pozo madre" y varios pozos verticales (lumbreras, espe- } \\
\text { juelos, etc.). Algunos de estos sistemas alcanzan varios kilómetros de longitud y contabilizan decenas de } \\
\text { pozos verticales. }\end{array}$ \\
\hline Cimbra o tajea & $\begin{array}{l}\text { Galería abierta en los depósitos de una rambla y construida de forma que las aguas del freático se filtren } \\
\text { por techo y paredes. Suelen tener pozos verticales a lo largo de su desarrollo. }\end{array}$ \\
\hline $\begin{array}{l}\text { Galería asociada a presa subálvea (antepuesta o } \\
\text { inscrita en la presa) }\end{array}$ & $\begin{array}{l}\text { En los depósitos de un cauce de fluir intermitente, se sitúa una presa que corta la circulación subsuper- } \\
\text { ficial, a la que se le antepone o inscribe la galería con sus drenes (piqueras, mechinales, troneras). Suele } \\
\text { contar con pozos verticales para facilitar el funcionamiento del complejo hidráulico. }\end{array}$ \\
\hline
\end{tabular}

Fuente: elaboración propia según trabajos del Grupo E0A5-03 (GAPT) de la Universidad de Murcia y del Grupo ESTEPA de la Universidad de Valencia.

potencial superior a $900 \mathrm{~mm})$. Al estar cubierto e incluso enterrado bajo depósitos, apenas sufre de esa evaporación hasta que es alumbrado el caudal por la bocamina (Figura 3). Los arqueólogos han puesto de manifiesto su papel en la construcción de paisajes regados, en los oasis 9 .

Esta investigación presta atención a tres complejos hidráulicos de captación de subálveos y a los rasgos del sistema hidrosocial asociado a cada uno de ellos. Se han seleccionado tres que están activos y con los que se obtienen unos recursos de agua de gran calidad, con importancia socioeconómica a nivel local: el complejo hidráulico de la rambla de Béjar y, los de Los Cotes-Cegarras y Caño-Contracaño en la rambla de Nogalte.

\section{Metodología}

Esta investigación es un estudio regional, diacrónico y comparado, de pequeña hidráulica para alumbrar freáticos próximos a la superficie, como sucede con la circulación subsuperficial del lecho de cauces del tipo rambla. El estudio tiene un marcado carácter geográfico-histórico, con trabajo de campo, labor de archivo y entrevistas a los usuarios de estos sistemas.

Las fases de trabajo han sido: Las salidas y notas de campo para contrastar con la realidad (localizar, medir, fotografiar, levantar alzados, describir en qué estado se encuentra el sistema, etc.). La visita a archivos, a la búsqueda de documentación que sirva para preparar el estudio diacrónico y comparar con otros lugares, etc. Las entrevistas a gestores y usuarios del agua, cuando la gestión del agua en estos espacios hidráulicos de oasificación frente a desertificación, es vital, además de la percepción de la valoración del

\footnotetext{
9. Charbonnier \& Hopper, 2018.
}

patrimonio hidráulico y del paisaje asociado a estos recursos hídricos. Se emplean técnicas de investigación cuantitativa (tratamiento de las precipitaciones y de los aforos) y cualitativa (Panel de Expertos y Matriz DAFO). También es un análisis geográfico regional aplicado por las nuevas funcionalidades del dren que se estudian y proponen.

Para su ubicación y desarrollo lo primero es que exista el interés de un particular o de un grupo social para captar la circulación subsuperficial. Se hace necesario conocer aquellos tramos del cauce en los que, bajo varios metros de materiales permeables, existen ciertas condiciones de impermeabilidad y dureza (caso de un conglomerado o un estrato de material metamórfico, etc.) donde asentar la presa subálvea. Una vez alumbradas las aguas se emplean en diversos usos, que se hacen sucesivos en los casos de no ser consuntivos (Figura 3): abastecimiento de personas y ganados (caños y abrevaderos), usos domésticos (lavaderos) e industriales (molinos hidráulicos) y el riego ${ }^{10}$.

Estos sistemas pueden estudiarse como formas de aprovechamiento integral del agua en medios secos, al producirse una combinación de recursos (superficiales, subálveos y subterráneos) y una sucesión de usos en su explotación (abastecimiento de personas y ganado, uso doméstico, uso industrial y riego ${ }^{11}$. Grandes oasis como el de Tafilait en Marruecos tienen su origen en las aguas captadas por qanats o khettaras ${ }^{12}$.

Hemos organizado el trabajo de investigación desde el paradigma del agua como un bien escaso que obliga a buscar recursos para ampliar la oferta y a gestionar mejor la demanda, algo vital para el desarrollo de regiones secas, en el marco del ciclo integral del agua (Directiva Marco del Agua, 2000/60/CE) y comprometido en la consecución

\footnotetext{
10. Gil Meseguer, Martínez Medina y Gómez Espín, 2011.

11. Gómez Espín, 2005, 102.

12. Lightfoot, 1996.
} 
Figura 3. Bocamina, abrevadero y lavadero del Caño de Béjar

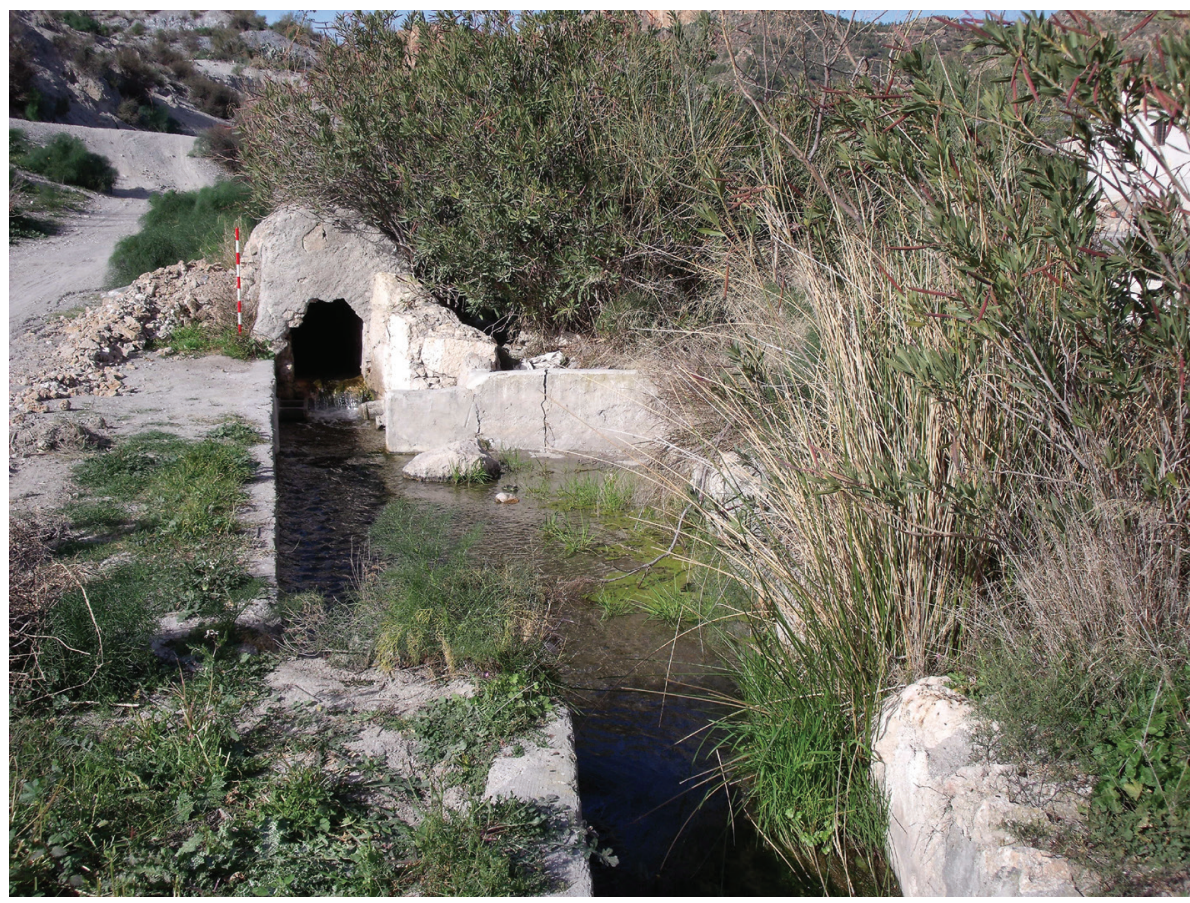

Fotografía de Gómez-Espín, 2 de enero de 2013.

de los Objetivos de Desarrollo Sostenible (ODS). Se espera con esta investigación contribuir a la propuesta de medidas de adaptación al calentamiento global y a escenarios de Cambio Climático apuntados por la Cumbre sobre la Acción Climática, Nueva York 2019, y por redes globales como Higher Education Sustainability Iniciative, Agenda 2030, etc., de mitigación y adaptación a la crisis climática.

\section{Resultados $^{13}$}

Entre las cimbras o tajeas funcionales del Sureste de España se pueden señalar en la Región de Murcia, la de la Presa de Arriba del Román en la rambla del Moro-La Raja, y la del Caño Viejo en la rambla de Nogalte. En la provincia de Almería, las de los términos de Pulpí, Cuevas del Almanzora y Huércal-Overa, caso de la del paraje de Las Canalejas conocida como la galería "La Mucha", la de la "Balsa Redonda", y también la denominada "Nacimiento de las Agüicas". En el paraje del Vizcaíno la galería de "El Balsón"14. En el lecho del Almanzora

\footnotetext{
13. Los doctores Gil y Gómez vienen estudiando estos ejemplos del pozo horizontal (galería), inscrito o asociado a presa subálvea, desde hace casi treinta años. Unas veces solos (Gómez Espín y Gil Meseguer, 1993) y otras con un conjunto de colaboradores (Aliaga Sola, Martínez Medina, López Fernández, Albaladejo García, Bernabé Crespo, etc.). Últimamente han localizado nuevos sistemas y buscado nuevas funcionalidades: Gil Meseguer, García Sánchez y Gómez Espín, 2013. Martínez-Medina, Gil-Meseguer \& GómezEspín, 2018.

14. Gil Meseguer et al., 2014, 20-21.
}

destacaba la Cimbra del Cebollar o Mina de Toribio, cuyos trabajos se prolongaron más de ciento cincuenta años, entre 1719 y 1878. En la dirección intervinieron sucesivamente Toribio Martínez de la Vega, Idelfonso Cerdá, Juan Fernando Feigenspan y Antonio Farces Yesares $^{15}$. La galería se prolongaba unos tres kilómetros entre la Huerta del Cebollar y el paraje de la Cueva o Piedra Negra. El vano de la galería era de 1,80 metros de alto por 1,25 metros de ancho; el trayecto de la cimbra se hallaba salpicado por 47 lumbreras. Ha quedado sin función bajo el embalse de Cuevas ${ }^{16}$.

A veces el caudal alumbrado es considerable. La cimbra que atraviesa el lecho del río Luchena, aguas abajo del embalse de Valdeinfierno, actúa como salida natural del acuífero Pericay (los Ojos de Luchena) y llega a captar para el regadío de Lorca hasta $10 \mathrm{Hm}^{3} /$ año $^{17}$.

En otros casos el caudal es pequeño, como en la cimbra de la Presa de Arriba del Román, en la rambla del Moro-La Raja, entre los términos de Jumilla y Abarán (Región de Murcia). Construida en los sedimentos adosados a la presa, alumbra un caudal aforado variable de 5 a 20 litros. Desde la bocamina, por una pequeña acequia de 1.750 metros de longitud, en la margen derecha de la rambla,

\footnotetext{
15. Gómez Espín, 2016, 133.

16. Fernández Bolea, 2006, 142.

17. López Fernández, 2009.
} 
se conduce el agua hasta una alberca, de origen romano, en las Casas de Román (Figura 4$)^{18}$. Alfredo Morales Gil indicaba que el caudal captado se depositaba en una balsa para atender las necesidades de las villae desdeépoca romana hasta mediados del siglo $\mathrm{XX}^{19}$.

En el área de estudio, sobresale -como cimbra en funcionamiento- la del Caño Viejo en la rambla de Nogalte (Figura 5). Su origen se remonta a época islámica. En documentos del Archivo Municipal de Lorca ${ }^{20}$, se menciona como pozo-fuente o conducto-cubierto de lumbreras. Es una cimbra abierta en los sedimentos de la rambla, que describe una forma de ese (S) para tener mayor superficie por la que filtrarse las aguas al interior de la galería (por las paredes y techo). Cuenta con 15 pozos verticales (lumbreras) ${ }^{21}$.

Se inicia la cimbra en la desembocadura del Barranco Cañar (margen izquierda de la rambla) y cruza el lecho drenando las aguas subsuperficiales. Actualmente se unen las alumbradas por el Contracaño, tras un recorrido de 312 metros. El vano de la galería es de 1,10 $\mathrm{m}$ de alto $\mathrm{x}$ $0,60 \mathrm{~m}$ de anchura. Continúa por la margen derecha de la rambla, captando las aguas que escurren y se infiltran de la falda del Cabezo del Castillo. Todas las aguas son alumbradas en un caño (fuente y abrevadero) y acumuladas en una balsa (de más de mil cien $\mathrm{m}^{3}$ de capacidad), hoy convertida en cisterna y reducida a $960 \mathrm{~m}^{322}$ (Figura 6).

Otros sistemas de galería drenante inscritos o asociados a presa subálvea son la presa de la Fuente del Oro en el tramo urbano del Guadalentín, la de la rambla de Béjar, las de las ramblas del Ramonete, Fuente Álamo o del Albujón, y las de Los Cotes-Cegarras y Caño-Contracaño en la rambla de Nogalte.

En la rambla de Béjar, aguas abajo del Estrecho o Cortado de Las Peñas, se cuenta con una presa subálvea (de 160 metros) dispuesta en diagonal en los sedimentos de la rambla, que capta el agua intersticial mediante una serie de troneras y es del modelo de galería inscrita (Figura 7). Del extremo derecho arranca la galería de conducción con lumbreras cada 50 metros. Tras 950 metros de recorrido alumbra las aguas por la bocamina hasta un abrevadero y lavadero, y finalmente a la

\footnotetext{
18. Gómez Espín, 1994, 113.

19. Morales Gil, 2001, 17: “Una presa de derivación de avenidas con un canal menor para trasladar hasta las villae el caudal de la circulación hipodérmica que mana por la parte inferior de la presa, para ser regulado en un estanque de fábrica de mampostería".

20. A.M.L. Sección "Justicia”. Caja 10. Año 1775.

21. Gómez Espín, 2004, 86.

22. Gil Meseguer y Gómez Espín 2006.
}

balsa $^{23}$. La fuerza erosiva de la avenida de San Wenceslao (de 28 de septiembre de 2012) descarnó buena parte de la presa e introdujo sedimentos al interior de la galería por varias de sus lumbreras tras una extracción excesiva de gravas y arenas realizada sin control a fines de 2007 en el tramo final de la rambla.

La Comunidad de Propietarios del Caño y Balsa de Béjar es la que administra las aguas alumbradas y se encarga del mantenimiento del complejo hidráulico, en función de la participación en las 336 horas de agua de la tanda de 14 días. El 10 de enero de 2020 contaba con 17 propietarios, de los que cuatro de ellos reunían más de la mitad (el 54,47 \%) de dichas horas de agua, y los que tenían menos de 10 horas de agua apenas suponían el 7,75\% del total de participación (Tabla 2).

Desde 1926, se cuenta en la cabecera de la rambla de Nogalte con el complejo hidráulico del sistema de Los Cotes-Cegarras, del tipo de galería inscrita en presa subálvea. Iniciado para llevar las aguas alumbradas del subálveo a la Base Naval de Cartagena, fue uno de los posibles orígenes de aguas para la Mancomunidad de Canales del Taibilla. Los aforos no eran suficientes para las necesidades de Cartagena y su Base Naval, pero sí para las necesidades de abastecimiento, energía industrial y riego de la parte alta de la rambla de Nogalte. Las aguas captadas se conducen a una balsa y son explotadas por una Sociedad de Aguas ${ }^{24}$ (Figura 8).

Tras acumularse en la balsa, las aguas permitían mover las piedras de tres molinos hidráulicos de cubo para la molienda de cereal, transformados también en almazaras para moler aceituna. Recientemente hablamos con Pedro "el de la Almazara", que nos indicó que también realizaban dicha labor con energía eléctrica (Figura 9).

La Comunidad de Propietarios de la Balsa de Los Cegarras está formada por algo más de 30 propietarios, que reúnen las 360 horas de la tanda de 15 días. En cuanto a número predominan los de menos de tres horas de agua, reúnen casi las dos terceras partes. Sin embargo, en cuanto a la participación en horas, cinco propietarios reúnen más de la mitad de ellas.

El sistema más original y que continúa en funcionamiento desde 1890 es El Contracaño en la rambla de Nogalte (Figura 10). Se localiza a la altura del tramo donde se asienta y extiende en sus márgenes la población de Puerto Lumbreras (Región de Murcia).

Es una presa subálvea con una galería drenante antepuesta para captar el agua intersticial del gran depó- 
Figura 4. Bocamina de la cimbra de la Presa de Arriba del Román

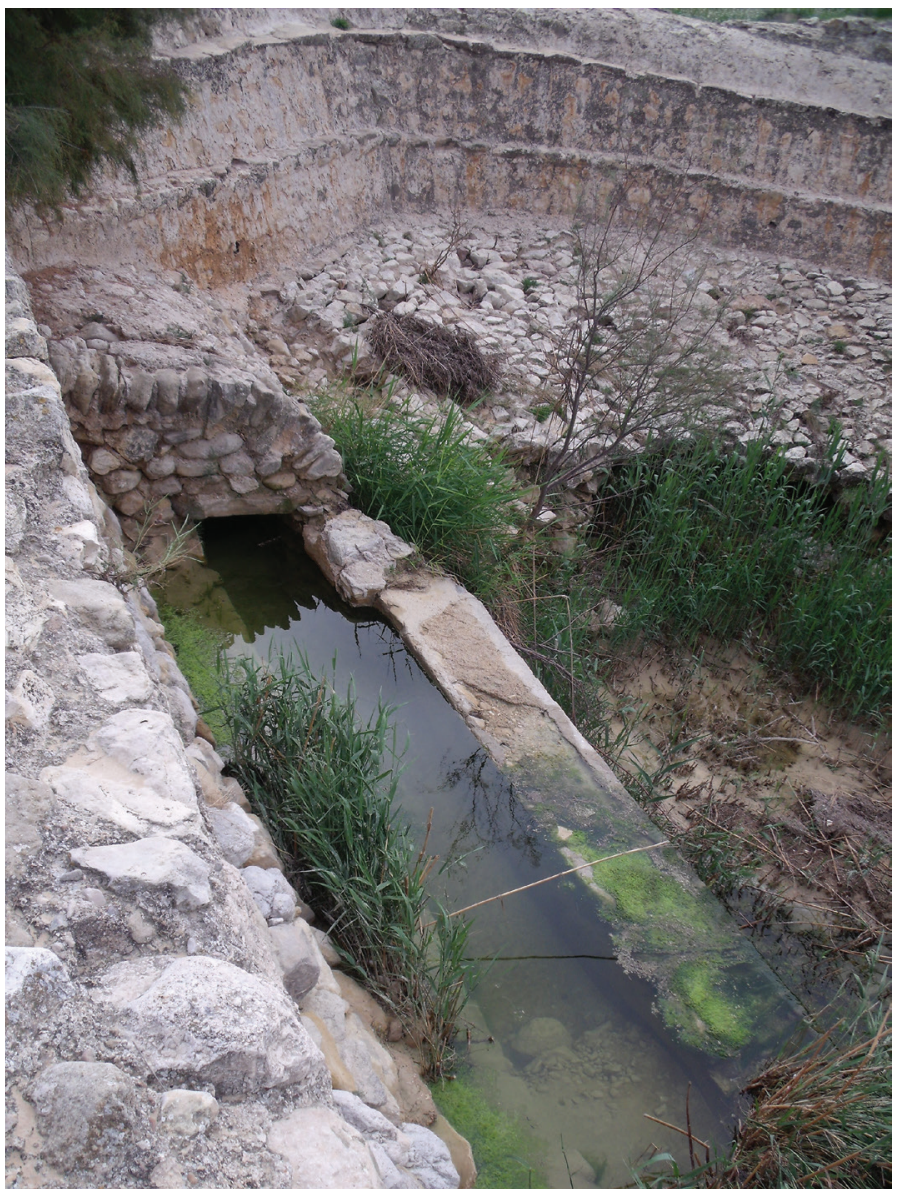

Fotografía de Gómez-Espín, 21 de noviembre de 2015.

Figura 5. Rehabilitación y limpieza del Caño Viejo en el lecho de la rambla de Nogalte, en 1995

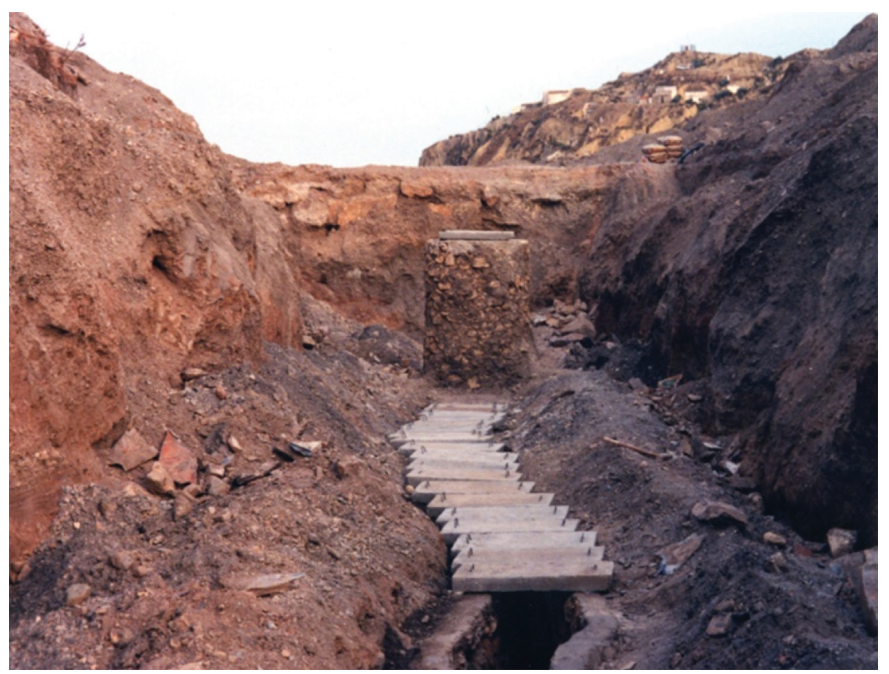

Fuente: Gómez-Espín, 2004, 109.
Figura 6. Cisterna de la antigua balsa de Lumbreras

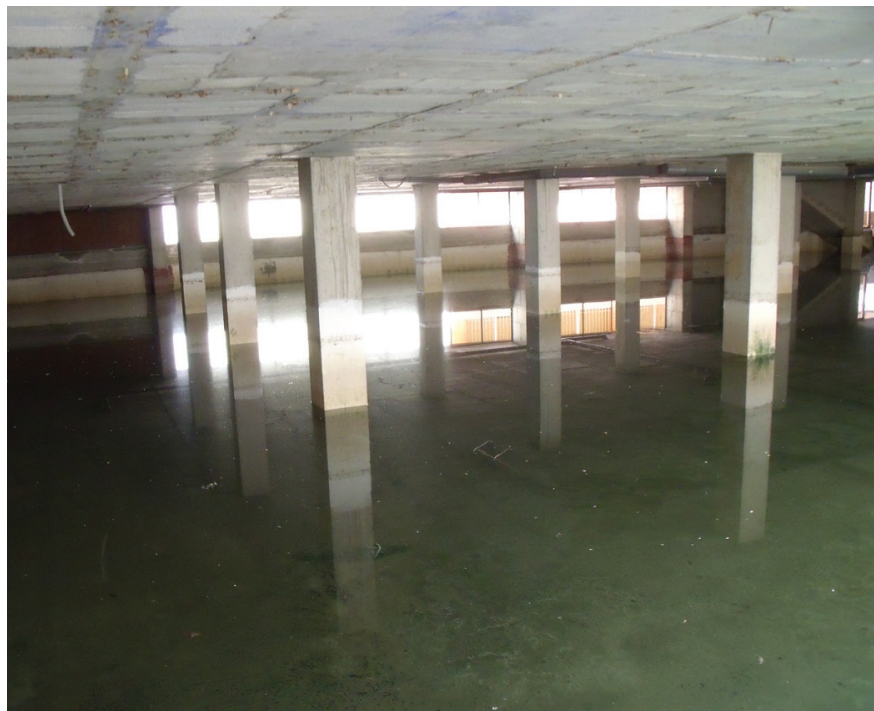

Fotografía de Gómez Espín, 21 de diciembre de 2007. 
Figura 7. Presa subálvea en la rambla de Béjar, tras la avenida de San Wenceslao

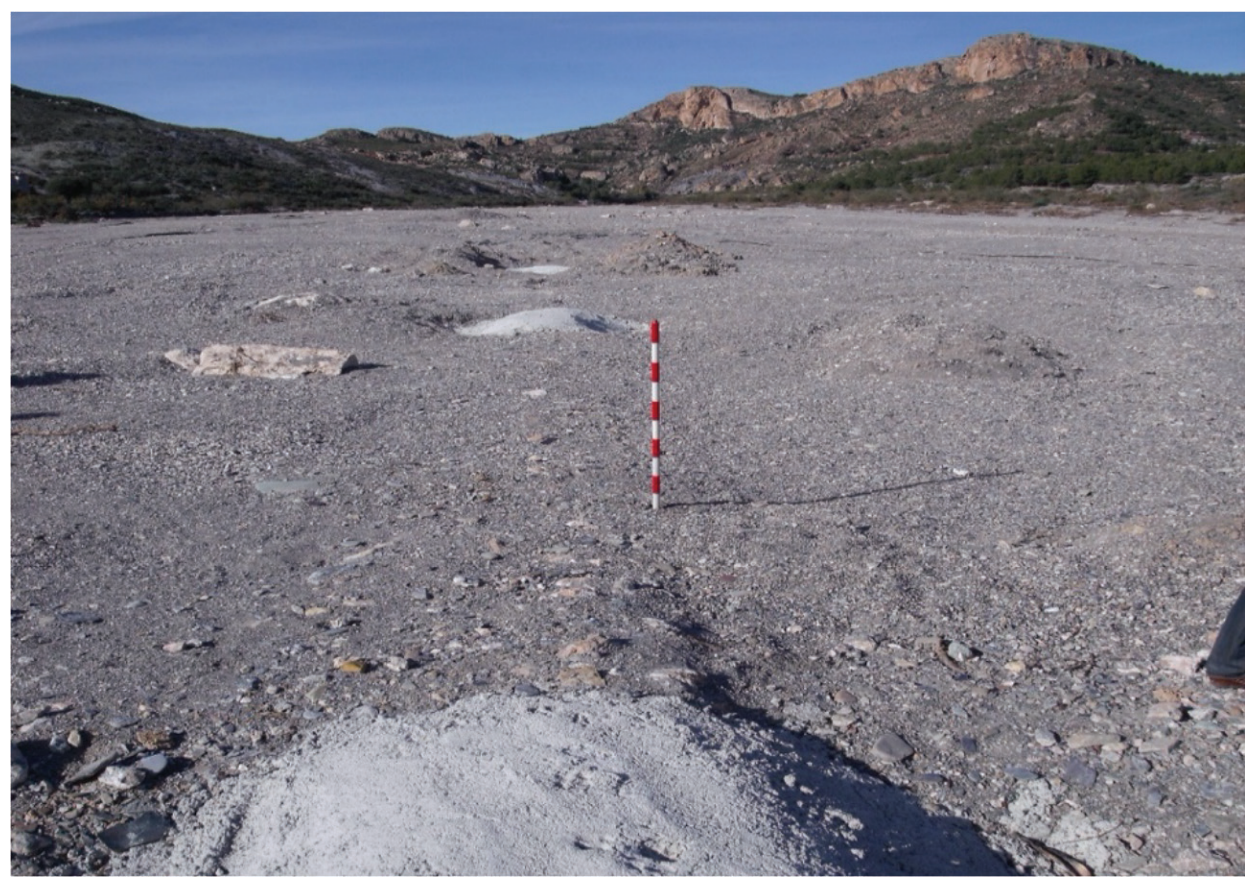

Fotografía de Gómez-Espín, 2 de enero de 2013.

sito detrítico que es el cauce de la rambla. Para su construcción se abrió una gran zanja o tajea en los depósitos del cauce de unos 15 metros de anchura por unos 120 metros de largo; en forma de arco transversal (diagonal). Con una profundidad de más de 8 metros, hasta llegar al impermeable de base, un conglomerado que los más ancianos decían "era el firme de los montes que se unían bajo el lecho de la rambla". La presa es de forma trapezoidal, con una base de 4 metros y la cúspide de 1 metro, realizada en piedra y cal hidráulica.

Adosada a la presa y antepuesta, se construyó una galería drenante (con vano de 1,80 metros de altura por 0,80 metros de anchura, con 7 lumbreras). En la parte inferior de la galería, a unos 0,30 metros del suelo, se situaban unos orificios (piqueras, troneras, mechinales, etc.) en contacto con el álveo de la rambla (un vaso enterrado de 120 metros de anchura por 8 metros de profundidad y 1.200 metros de largo) para que penetren las aguas subsuperficiales, según la mayor o menor saturación de agua entre las gravas y arenas de la rambla. Cuando el vaso de embalse está saturado y la galería no puede captar toda el agua, esta aflora en superficie formando balsones como el de Peñas Blancas ${ }^{25}$.

Tanto el Caño Viejo como el Contracaño y las tierras próximas que vierten aguas a la rambla de Nogalte pertenecen a una Comunidad de Propietarios creada como
TABLA 2. ESTRUCTURA DE LA PROPIEDAD EN LA SOCIEDAD DE AGUAS DEL CAÑO Y BALSA DE BÉJAR

\begin{tabular}{|c|c|c|}
\hline Propietarios & Horas de agua & Participación (\%) \\
\hline 1 & 58,5 & 17,41 \\
\hline 1 & 49,5 & 14,73 \\
\hline 1 & 41,0 & 12,21 \\
\hline 1 & 34,0 & 10,12 \\
\hline 1 & 27,0 & 8,04 \\
\hline 1 & 25,0 & 7,44 \\
\hline 1 & 18,0 & 5,36 \\
\hline 1 & 15,0 & 4,47 \\
\hline 1 & 14,0 & 4,17 \\
\hline 1 & 14,0 & 4,17 \\
\hline 1 & 14,0 & 4,17 \\
\hline 1 & 9,0 & 2,68 \\
\hline 1 & 6,0 & 1,79 \\
\hline 1 & 4,0 & 1,19 \\
\hline 1 & 3,0 & 0,89 \\
\hline 1 & 2,0 & 0,60 \\
\hline 1 & 2,0 & 0,60 \\
\hline Total 17 & 336,0 & 100,00 \\
\hline
\end{tabular}

Fuente: Elaboración propia a partir de la información de la Sociedad de Aguas del Caño y Balsa de Béjar (10 de enero de 2020).

\footnotetext{
25. Gómez Espín, 2004, 90.
} 
Figura 8. Balsa que recoge las aguas alumbradas por el sistema de Los Cotes-Cegarras

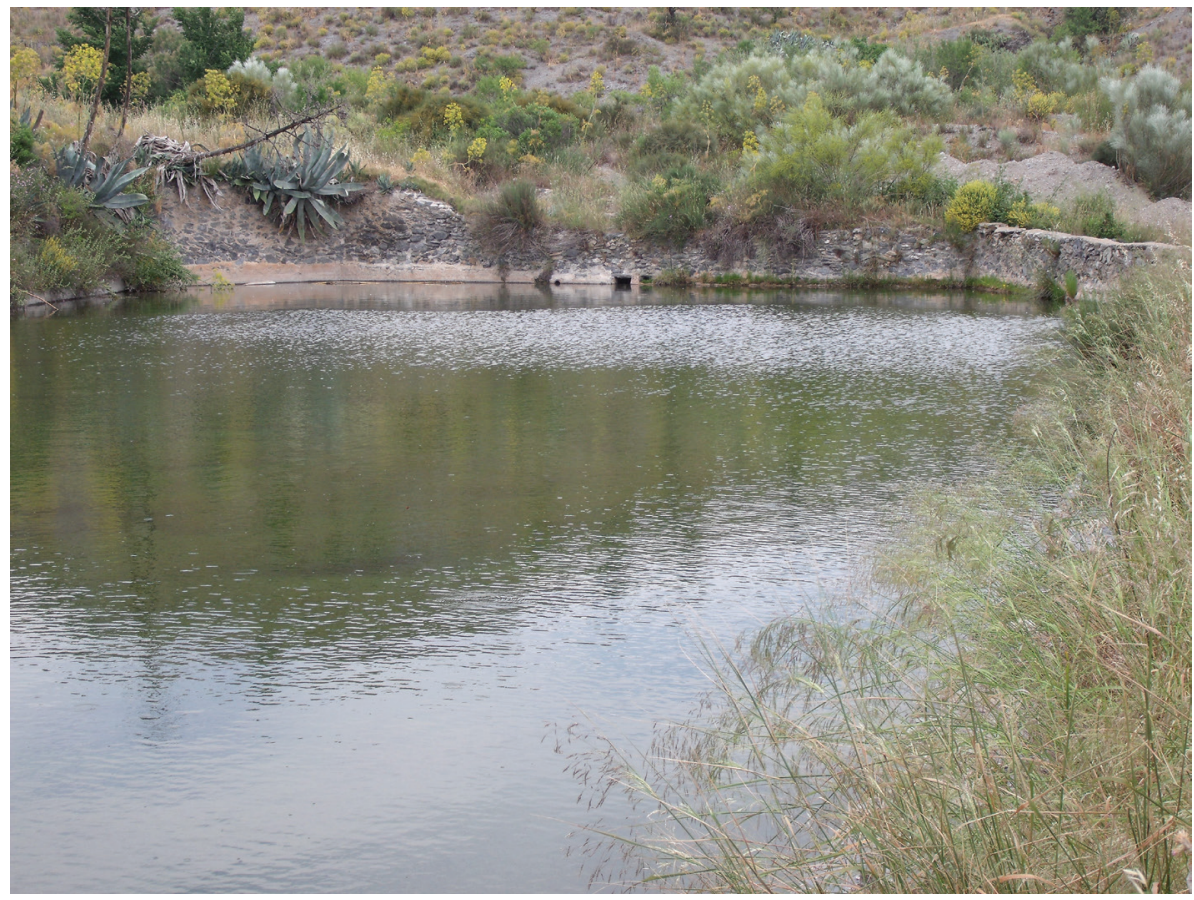

Fotografía de Gómez-Espín, 5 de abril de 2009.

tal en 1926: Comunidad de Propietarios de las Aguas del Caño y Balsa de Lumbreras ${ }^{26}$. Para la distribución de agua existe la figura del Repartidor (fiel de aguas), que la distribuye según las horas y minutos de cada propietario. Cuando alguno de ellos no deseaba hacer uso de su turno en la tanda, el Repartidor (hombre de confianza entre el dueño y el usuario) le fijaba un precio para que otra persona del perímetro regable pudiera disponer de ese turno de agua ${ }^{27}$. El 21 de agosto de 2014, la Comisaría de Aguas de la Confederación Hidrográfica del Segura declaró constituida la Comunidad de Regantes del Caño de Puerto Lumbreras (Tabla 3).

En cuanto a la estructura de la propiedad a finales de 2019 (10 de diciembre de 2019), 135 propietarios reunían las 336 horas de la tanda de 14 días. Con más del 5 $\%$ de participación solo había cuatro propietarios, y reunían más de un tercio del total de las 336 horas (112,08 horas, el 33,35 \% de la participación total). Estos socios mayoritarios están relacionados con empresas hortofrutícolas, de floricultura y semilleros, que están interesados en disponer para sus producciones de agua de gran calidad, como las alumbradas por el Caño y Contracaño.

Entre las galerías con lumbreras (qanats) que en su recorrido atraviesan el lecho de una rambla y se convierten en galería drenante inscrita en presa subálvea,

\footnotetext{
26. Gómez Espín, 2004, 133.

27. Gil Meseguer, Martínez Medina y Gómez Espín, 2012, 321-323.
}

destacaremos la de Las Tobarrillas (Yecla) (Figura 11), la de los Pozos de la Fuente (en Avilés-Alto Lorca), en Fuente Álamo la del Canal del Sifón al atravesar la rambla del pueblo y el tramo de Los Celdranes al atravesar la rambla de La Murta, la de Los Molinos o río Espuña en Alhama de Murcia, y la de Góñar al atravesar las ramblas de Los Venados y de El Fraile, en el límite entre las provincias de Murcia y Almería ${ }^{28}$.

El qanat de Las Tobarrillas, en Yecla, cuenta con más de dos mil quinientos metros de galería, con pozo madre y casi treinta espejuelos (Figura 11). El agua del sistema se acumulaba en una balsa (con capacidad para 1.230 metros cúbicos) y se aprovechaba para uso doméstico (lavadero), riego y abastecimiento para el ganado ${ }^{29}$.

En la rambla de Fuente Álamo y en relación con el qanat de Casa Girón, Castejón hace referencia a dos presas subálveas ${ }^{30}$. En los términos de Fuente Álamo y Murcia, el sistema de galería con lumbreras de la Sociedad Amistad y Lucro (en el tramo de Los Celdranes) se

\footnotetext{
28. Gil Meseguer, Martínez Medina y Gómez Espín, 2011, 5.

29. Gil Meseguer y Gómez Espín, 2006, 54.

30. Castejón Porcel, 2014, 202: “Indicadas en el mapa realizado por D. Juan José Sánchez Pescador en 1828 y en el informe de D. Constantino Germán realizado en 1852. La avenida del 28 de septiembre de 2012 sacó a la luz estas construcciones en el lecho de la rambla. La presa superior (a la altura del actual IES Ricardo Ortega) era una presa subálvea con galería inscrita que cruzaba la rambla con más de $30 \mathrm{~m}$ de longitud, y disponía de cuatro contrafuertes aguas abajo con objeto de soportar el empuje de las aguas (avenidas). La presa inferior estaría en la confluencia de la rambla de la Azohía con la rambla de Fuente Álamo".
} 
Figura 9. Primer molino-almazara, en la margen izquierda de la rambla de Nogalte, en el sistema de Los Cotes-Cegarras

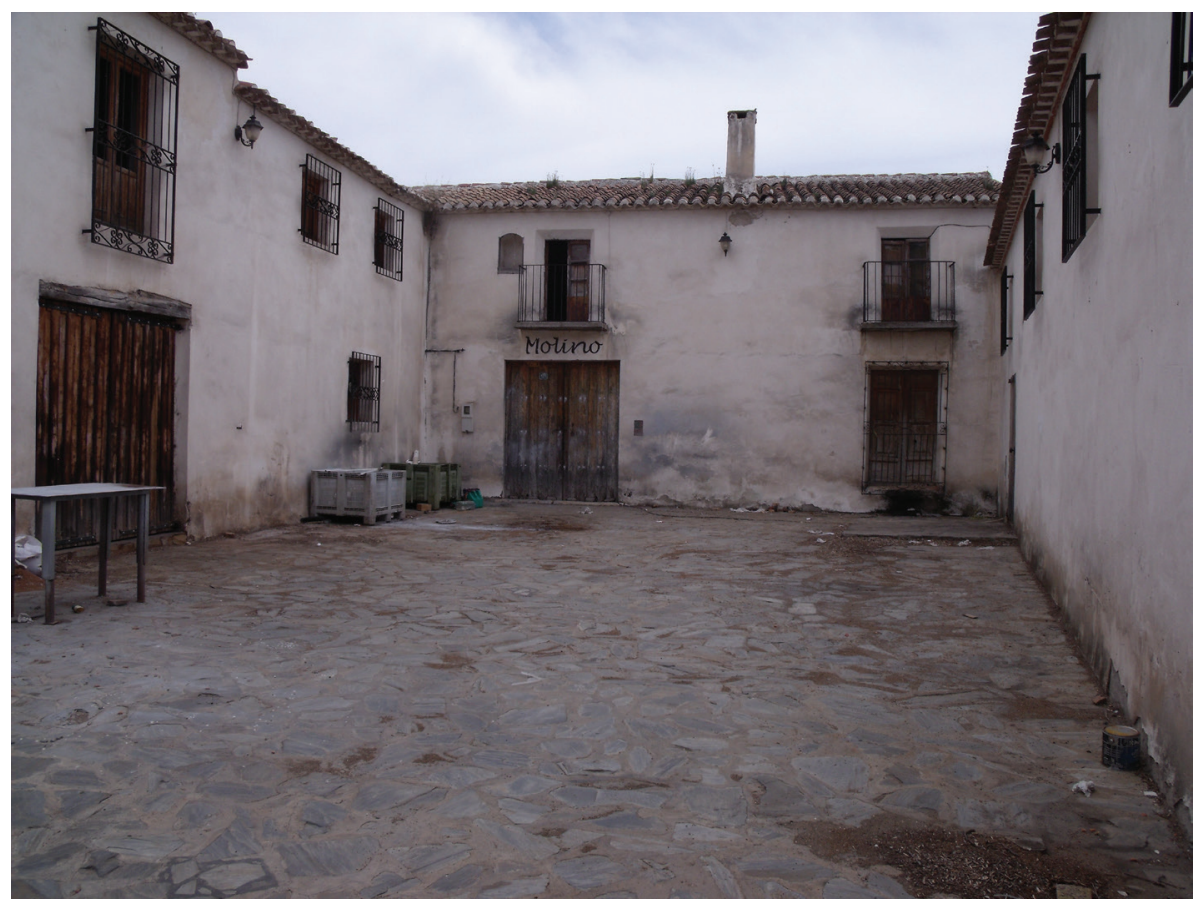

Fotografía de Gómez-Espín, 5 de abril de 2009.

convertía en presa subálvea con galería inscrita al atravesar la rambla de La Murta, continuaba como galería hacia Balsapintada con construcciones como el Canal del Sifón, al paso del ramblizo del Correo ${ }^{31}$.

Al SE del Cabezo de La Jara, arranca - de la rambla de Los Derramadores- la galería con lumbreras de Góñar, que al atravesar el lecho de las ramblas de Los Venados y El Frayle se convierte en presa subálvea. Acaba en Góñar en la fuente de los Caños y el lavadero (Figura 12), y el caudal sobrante se lleva a una balsa de acumulación desde donde se distribuye para riego.

En la rambla de Oria-Albox, el qanat de la Fuente del Marqués se comporta como galería inscrita en presa subálvea al atravesar el lecho de dicha rambla (afluente en la margen izquierda del Almanzora) ${ }^{32}$.

\section{Conclusiones}

La mayoría de las galerías drenantes (minados, cimbres, qanats, etc.) están abandonadas y algunas hasta desaparecidas, como la de Los Arejos en Águilas (Murcia) ${ }^{33}$. Estas galerías y presas subálveas sufren daños con los terremotos y con las grandes avenidas, a veces no se reconstruyen. Así ha sucedido con la presa de la Fuente

\footnotetext{
31. Gómez Espín, Castejón Porcel y Gil Meseguer, 2012, 242.

32. Gil Meseguer, 2016, 104. Gómez Espín, 2016, 130.

33. Gil Meseguer y Gómez Espín, 1993, 139.
}

del Oro, situada en el Guadalentín (entre la Peña y la Velica). La Fuente ha sido rehabilitada, en el año 2017, en la margen derecha del río-rambla, dentro del entramado urbano de Lorca.

Entre los motivos por los que estos sistemas han dejado de ser funcionales, hay que señalar la falta de mano de obra experta en su mantenimiento por el éxodo rural, la sobreexplotación de acuíferos próximos a estos sistemas hidráulicos que ocasiona bajada de caudales y hasta que se sequen, y la competencia de otros modos de producción (agriculturas intensivas de exportación y desarrollo de urbanizaciones), que fomentan el abandono de estos espacios de oasificación y paisajes de oasis $^{34}$.

En los últimos años, se observan motivos para la rehabilitación de estos sistemas y para la revitalización de las técnicas empleadas. Es el caso de la nueva valoración que se hace por la calidad de las aguas alumbradas y el escaso gasto energético necesario en su funcionamiento, circunstancias que han llevado a rehabilitar los complejos hidráulicos de Casa Herrera y del Partido de Los Álamos, ambos en Jumilla (Figura 13).

Se ha aprovechado la utilidad del dren estableciéndolo entre invernaderos y en laterales de caminos rurales para captar el agua de las escorrentías superficiales con la doble finalidad de acumularla y evitar las rotu-

34. Martínez Medina, Gil Meseguer \& Gómez Espín, 2018. 
Figura 10. Limpieza del Contracaño en la rambla de Nogalte. Modelo de galería drenante antepuesta a presa subálvea

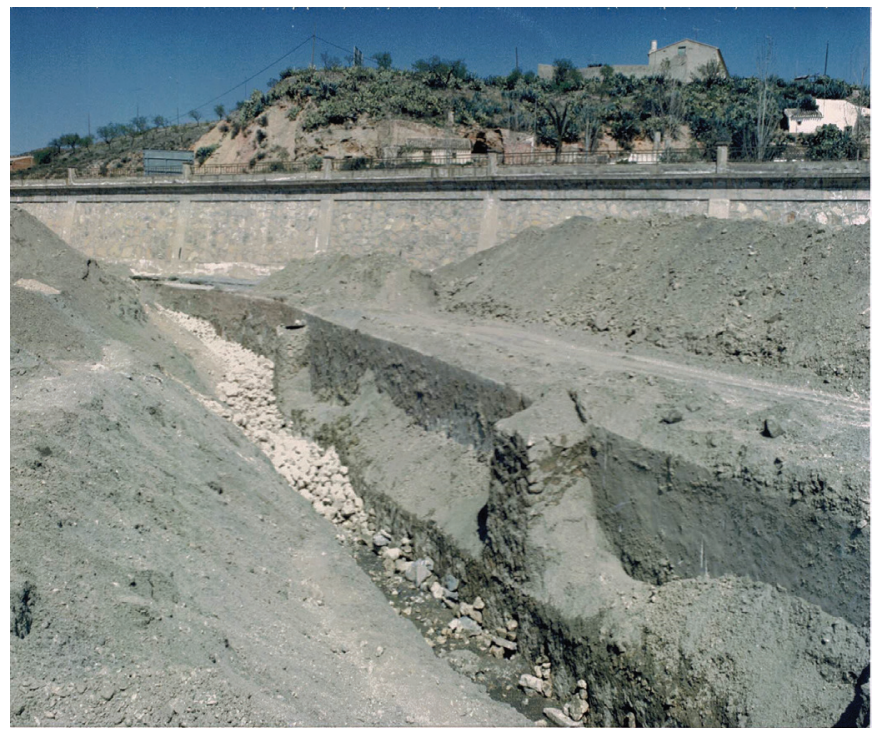

Fuente: Gómez-Espín, 1995.

Figura 11. Galería inscrita en presa subálvea, al paso del qanat por la rambla de Las Tobarrillas en Yecla

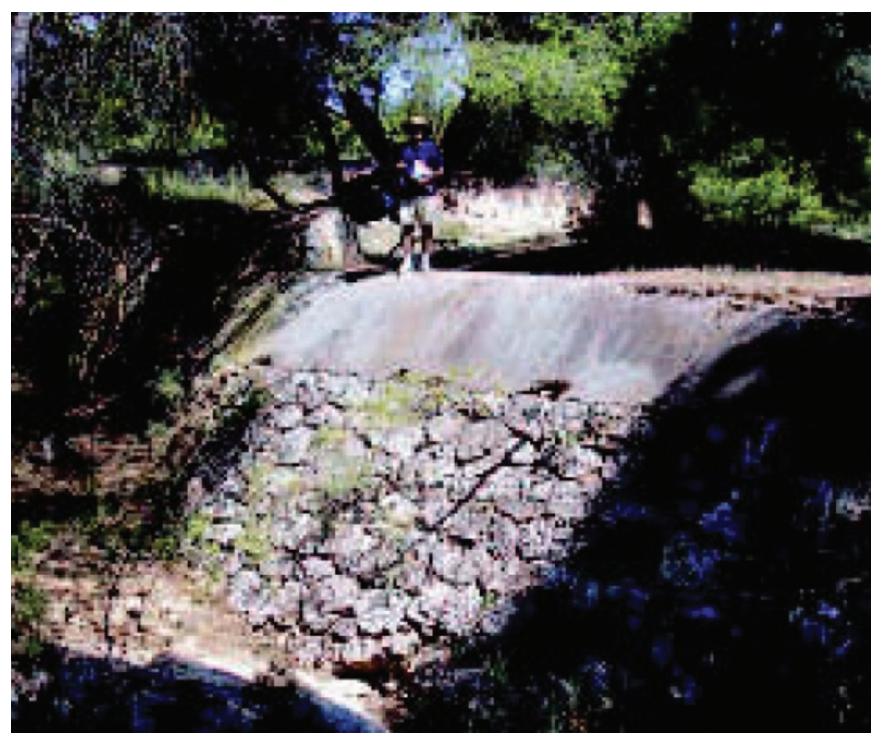

Fuente: Gil y Gómez (Coords.), 2006, 49 (Fotografía de Ignacio Aliaga).
TABLA 3. ESTRUCTURA DE LA PROPIEDAD EN LA COMUNIDAD DE REGANTES DEL CAÑO DE PUERTO LUMBRERAS

\begin{tabular}{cccc}
\hline $\begin{array}{l}\text { Intervalo de } \\
\text { participación de } \\
\text { horas de agua (\%) }\end{array}$ & $\begin{array}{l}\text { Número de } \\
\text { propietarios }\end{array}$ & Horas de agua & $\begin{array}{l}\text { Participación } \\
\text { acumulada de horas } \\
\text { de agua (\%) }\end{array}$ \\
\hline $0,1-1,0$ & 115 & 115,42 & 34,35 \\
\hline $1,01-2,0$ & 10 & 52,50 & 15,63 \\
\hline $2,01-3,0$ & 4 & 33,00 & 9,82 \\
\hline $3,01-5,0$ & 2 & 23,00 & 6,85 \\
\hline $5,01-10,0$ & 3 & 58,58 & 17,43 \\
\hline Más de 10,01 & 1 & 53,50 & 15,92 \\
\hline Total & 135 & 336,00 & 100,00 \\
\hline
\end{tabular}

Fuente: Elaboración propia con los datos suministrados por la Comunidad de Regantes del Caño de Puerto Lumbreras.
Figura 12. Fuente de Los Caños y lavadero de Góñar

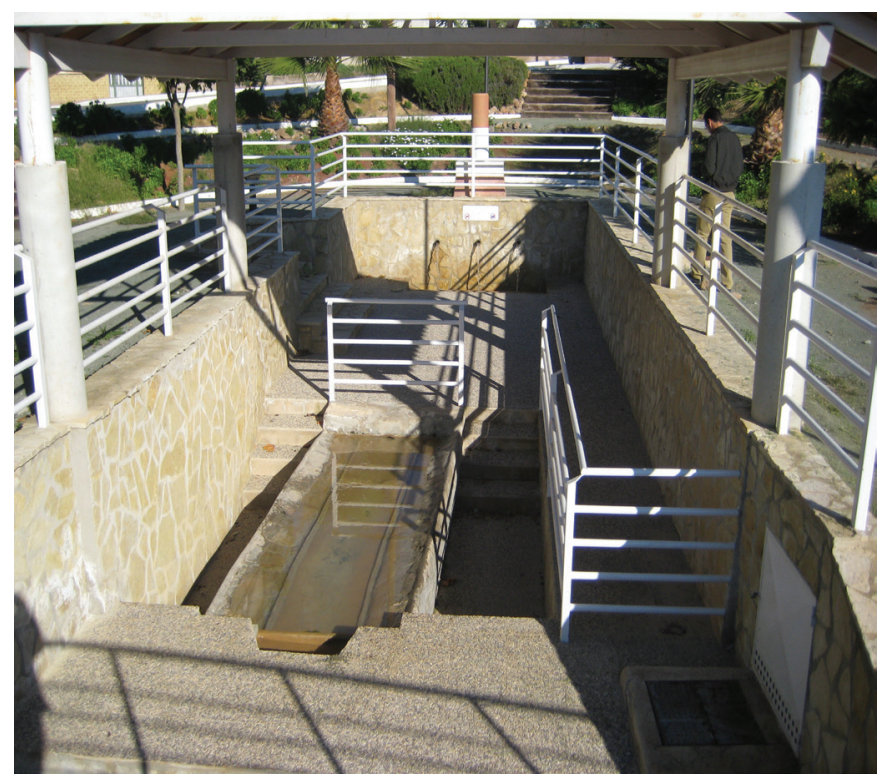

Fotografía de Gómez Espín, 24 de octubre de 2007. 
Figura 13. Rehabilitación del qanat de Casa Herrera (Jumilla)

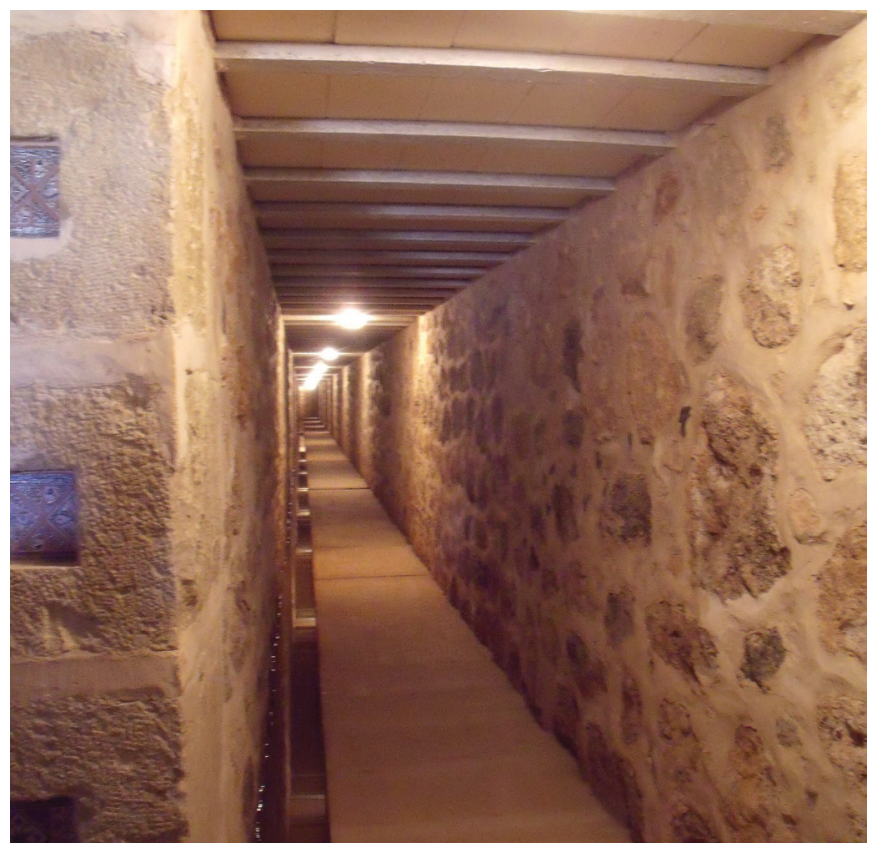

Fotografía de Gómez-Espín, 10 de enero de 2012.

ras que pueden ocasionar en eventos de lluvias de gran intensidad horaria. Empresas como Barberet \& Blanc, en Puerto Lumbreras, practican estos modelos de ordenación.

También es la técnica de las galerías drenantes la que la Comunidad de Regantes Arco Sur-Mar Menor establece, en el extremo SW de la cuenca del Mar Menor y a unos metros del borde de la laguna, para aprovechar las escorrentías subsuperficiales. Es un sistema de drenaje formado por la combinación de pozos horizontales que vierten las aguas alumbradas a un pozo vertical (cántara) donde se sitúan bombas impulsoras que las elevan a la planta desalobradora de la Comunidad de Regantes, situada junto a la EDAR Mar Menor. En ella son tratadas (junto a las depuradas en la EDAR) para su regeneración y uso en riego. Esta labor facilita que las aguas cargadas de nitratos no penetren en la laguna alterando los ecosistemas ${ }^{35}$. Ante escenarios de Cambio Climático, debemos poner en valor sistemas como el del Caño y Contracaño, que generan un caudal variable y de gran calidad. Se convierten en un recurso endógeno de gran interés local. Son modelos de sostenibilidad (no hay sobreexplotación, ni contaminación ni impacto paisajístico) y de gestión integral, cuando se sucedían los distintos usos del agua (abastecimiento de personas y ganados con caños y abrevaderos, usos domésticos con lavaderos a lo largo de las conducciones, como fuerza motriz para molinos hidráulicos de cubo, y finalmente el riego). En la actualidad, estos volúmenes de agua son demandados por propietarios de fincas especializadas en hortofruticultura, en floricultura y semilleros, que necesitan aguas de calidad y generan bastantes empleos.

Son sistemas hidrosociales, que generan espacios de oasificación frente a la desertificación ${ }^{36}$. Permiten hacer frente a fenómenos extraordinarios y recurrentes en el Sureste como las sequías, las avenidas e inundaciones. Contribuyen a ordenar el territorio -al crear reservas de agua con escasas pérdidas por evaporación, reservorios que se recargan en avenidas y disminuyen sus efectos catastróficos- para la adaptación al Cambio Climático y la mitigación de sus repercusiones.

\section{BIBLIOGRAFÍA}

Aliaga, I., Gil, E., Gómez, J. M., López, J. A. y Martínez, R. 2007: Sistemas locales de recursos propios de agua en la Región de Murcia: Minados y Galerías. Murcia, Universidad de Murcia.

Barceló, M., Carbonero, M. A., Martí, R. y Rossello-Bordoy, G. 1986: Les aigües cercades: Els qanats de l'illa de Mallorca. Palma de Mallorca, Institut d'Estudis Baleàrics.

Castejón Porcel, G. 2014: Galerías con lumbreras (qanats) en Fuente Álamo de Murcia: sistemas históricos de captación y canalización de aguas. Murcia, Ayuntamiento de Fuente Álamo de Murcia. Charbonnier, J. \& Hopper, K. 2018: "The Qanät: a multidisciplinary and diachronic approach to the study of groundwater catchment systems in archaelogy". Water History, 10, 3-11. https:// doi.org/10.1007/s12685-018-0214-9

Fernández Bolea, E. 2006: Agua y vida en Cuevas del Almanzora. Una historia de luchas y anhelos (Siglos XVI-XXI). Cuevas del Almanzora, Arráez Editores.

Gil Meseguer, E. 1987: Los Relieves Meridionales. Estudio geográffco de los relieves litorales comprendidos entre la desembocadura del río Almanzora (Almería) y de la rambla de Las Moreras (Murcia). Murcia, Universidad de Murcia, Ayuntamiento de Águilas.

Gil Meseguer, E. 2016: "Aprovechamientos de escorrentías superficiales eventuales y de subálveos en la rambla de Oria-Albox (Almería)", en Vera, J. F., Olcina, J., Hernández, M. (Eds.): Paisaje, cultura territorial y vivencia de la geografía. Alicante, Universidad de Alicante, 97-109. https://doi.org/10.3917/quae.aspe.2012.01.0315

Gil Meseguer, E. y Gómez Espín, J. M. 1993: "Galerías con lumbreras en el Sureste de España". Papeles de Geografía, 19, 125-145. https://revistas.um.es/geografia/article/view/44271/42391

\footnotetext{
36. Mongil y Martínez de Azagrall, 2007.
} 
Gil Meseguer, E. y Gómez Espín, J. M. (Coords.) 2006: Modelos de sostenibilidad en el uso del agua en la Región de Murcia. Murcia, Fundación CAJAMURCIA- Consejería de Industria y Medio Ambiente de la CARM-Universidad de Murcia.

Gil Meseguer, E., García Sánchez, R. M. y Gómez Espín, J. M. 2013: "Funcionalidad de las técnicas del pozo horizontal (galería) para la captación y conducción de aguas en el Sureste de España", en Hermosilla, J. (ed.): Las galerías de agua en la Región noroccidental de Túnez. Patrimonio hidráulico mediterráneo. Valencia, Universitat de València-Ministerio de Asuntos Exteriores y Cooperación, 147-158.

Gil Meseguer, E.; García Martínez, P. J.; Gómez Espín, J. M. y Almela Pérez, R. 2014: El dinamismo del regadío de Pulpí. Treinta años de Comunidad de Regantes. Murcia, Comunidad de Regantes de Pulpí.

Gil Meseguer, E., Gómez Espín, J. M. y Martínez Medina, R. 2012: "La investigación en España sobre los sistemas de captación y conducción de pozo horizontal (galería) asociada o no a presa subálvea", en Gómez, J. M. y Hervás, R. M. (Coords.): Patrimonio hidráulico y cultura del agua en el Mediterráneo. Murcia, Fundación Séneca-AECID-Campus Mare Nostrum, 189-202.

Gil Meseguer, E., Martínez Medina, R. y Gómez Espín, J. M. 2011: "Modelos de uso sostenible del agua: las galerías asociadas a presa subálvea". Scripta Nova. Revista electrónica de Geografía y Ciencias Sociales, XV (374), 10 de septiembre de 2011.

Gil Meseguer, E., Martínez Medina, R. y Gómez Espín, J. M. 2012: "Un modèle de gestion durable de l'eau d'irrigation dans le Sud-Est de l'Espagne. Le répartiteur des eaux du Caño y Balsa de Lumbreras (Murcie)", en De l'eau agricole à l'eau environnementale. París, Éditions QUAE, 315-324. https://doi. org/10.3917/quae.aspe.2012.01.0315

Gil Olcina, A. 1971: El campo de Lorca. Estudio de Geografía Agraria. Valencia, Facultad de Filosofía y Letras, Departamento de Geografía-CSIC.

Gil Olcina, A. 1993: La propiedad de aguas perennes en el Sureste Ibérico. Alicante, Universidad de Alicante.

Goblot, H. 1979: Les Qanats. Une technique d'acquisition de l'eau. París, Mouton Editeurs.

Gómez Espín, J. M. 1994: "Cambios socioeconómicos y espaciales en el umbral del s. XXI", en Carrasco Molina, J.: Abarán: acercamiento a una realidad. Murcia, Centro de Estudios AbaranerosCaja Murcia, 103-130.

Gómez Espín, J. M. 2004: Aprovechamiento integral del agua en la Rambla de Nogalte (Puerto Lumbreras-Murcia). Murcia, Universidad de Murcia.

Gómez Espín, J. M. 2005: "Galerías asociadas a presas subálveas, generadoras de recursos de agua en el Sureste de la Península Ibérica. El modelo del sistema de la Rambla de Béjar". Nimbus, 15-16, 101-120.
Gómez Espín, J. M. 2016: "Qanates, cimbras y minados en el Valle del Almanzora (Sureste de España)", en Vera Rebollo, J. F., Olcina Cantos, J. y Hernández Hernández, M. (Coords.): Paisaje, cultura territorial y vivencia de la geografía. Alicante, Universidad de Alicante, 125-141. https://doi.org/10.14198/LibroHomenajeAlfredoMorales2016-09

Gómez Espín, J. M., Castejón, G. y Gil Meseguer, E. 2012: "Un modelo de captación y conducción de aguas en medios semiáridos: el Canal del Sifón en Fuente Álamo de Murcia", en Gómez, J. M. y Hervás, R. M. (Coords.): Patrimonio hidráulico y cultura del agua en el Mediterráneo. Murcia, Fundación Seneca-AECID, 227-248.

Gómez Espín J. M. y Gil Meseguer, E. 1993: "Estado de la investigación sobre sistemas de captación de aguas subálveas en regiones áridas y semiáridas como Murcia". El estado actual de la investigación en Ciencia Regional en Murcia. Murcia, Instituto de Fomento de la Región de Murcia-Asociación Murciana de Ciencia Regional, 346-363.

Gómez Espín, J. M., Gil Meseguer, E., Aliaga Sola, I., López Fernández, J. A. y Martínez Medina, R. 2007: "Las galerías, construcciones para alumbrar agua de freáticos próximos en el NE de la Región de Murcia: minados con espejuelos en Jumilla". Investigaciones Geográficas, 42, 89-107. https://doi.org/10.14198/ INGE02007.42.04

Hermosilla Plá, J. (Coord.). 2006: Las galerías drenantes del Sureste de la Península Ibérica: uso tradicional del agua y sostenibilidad en el Mediterráneo español. Madrid, Ministerio de Medio Ambiente.

Hermosilla Plá, J. (Coord.) 2008: Las galerías drenantes en España. Análisis y selección de qanat(s). Madrid, Ministerio de Medio Ambiente y Medio Rural y Marino.

Hermosilla, J., Iranzo, E., Pérez, A., Antequera, M. y Pascual, J. A. 2004: "Las galerías drenantes de la provincia de Almería: análisis y clasificación tipológica". Cuadernos de Geografía, 76, 125-153.

Hernández Hernández, M. y Morales Gil, A. 2013: "Los aprovechamientos tradicionales de las aguas de turbias en los piedemontes del Sureste de la Península Ibérica: estado actual en tierras alicantinas". Boletín de la Asociación de Geógrafos Españoles, 63. 105-123. https://doi.org/70.21738/bage.1608

Iranzo García, E., Antequera Fernández, M. y Hermosilla Pla, J. 2010: "Identificación, evaluación y puesta en valor de un patrimonio hidráulico singular: las galerías drenantes de la Cuenca del Júcar". Investigaciones Geográficas, 53, 125-143. https://doi. org/10.14198/INGE02010.53.06

Lightfoot, D. R. 1996: "Moroccan Khettara: Traditional Irrigation and Progressive Desiccation". Geoforum, 27 (2), 261-273. https://doi. org/10.1016/0016-7185(96)00008-5

Lightfoot, D. R. 2000: "The Origin and Diffusion of Qanats in Arabia: New Evidence from the Northern and Southern Peninsula". The Geographical Journal, 166 (3), 215-226. https://doi. org/10.1111/j.1475-4959.2000.tb00021.x 
Llobet Reverter, S. 1958: "Utilización del suelo y economía del agua en la región semiárida de Huércal-Overa (Almería)". Revista Estudios Geográficos, 70, 5-21.

López Fernández, J. A. 2009: El agua y sus usos en el Campo Alto de Lorca. Región de Murcia. Murcia, Asociación Murciana de Ciencia Regional-CAM Caja Mediterráneo.

Magee, P. 2005: "The Chronology and Environmental Background of Iron Age Settlement in Southeastern Iran and the Question of The Origin of the Qanat Irrigation System". Iranica Antiqua, XL, 217-231. https://doi.org/10.2143//A.40.0.583210

Martínez-Medina, R., Gil-Meseguer, E. \& Gómez-Espín, J. M. 2018. "Research on qanats in Spain". Water History, 10, 339-355. https://doi.org/10.1007/s12685-018-0224-7

Mongil, J. y Martínez de Azagra, A. 2007: "Técnicas de recolección de agua y de oasificación para el desarrollo de la agricultura y la restauración forestal en regiones desfavorecidas". Cuadernos
Geográficos, 40 (1), 67-80. https://www.redalyc.org/articulo. oa?id=17104004

Morales Gil, A. 1968-1969: "El riego con aguas de avenida en las laderas subáridas". Papeles del Departamento de Geografía, 1, 167-183.

Morales Gil, A. 2001: Agua y Territorio en la Región de Murcia. Murcia, Fundación Centro de Estudios Históricos e Investigaciones Locales Región de Murcia

Morales Gil, A. y Box Amorós, M. 1993: "Barrancos y ramblas: su incorporación al entramado urbano en el Sureste peninsular". Investigaciones Geográficas, 11, 153-169. https://doi. org/10.14198/INGE01993.11.03

Morales Gil, A., Box Amorós, M. y Marco Molina, J. A. 1991: "El medio físico y la presa de Román (Jumilla): un emplazamiento favorable". Investigaciones Geográficas, 9, 69-80. https://doi. org/10.14198/INGE01991.09.09 